\title{
Erratum to: The Role of Structural Barriers in Risky Sexual Behavior, Victimization and Readiness to Change HIV/ STI-Related Risk Behavior Among Transgender Women
}

\author{
Jerris L. Raiford ${ }^{1}$ - Grace J. Hall ${ }^{1}$. Raekiela D. Taylor ${ }^{1}$ - David S. Bimbi ${ }^{2,3,4}$ • \\ Jeffrey T. Parsons ${ }^{3,4,5}$
}

Published online: 19 July 2016

(c) Springer Science+Business Media New York 2016

\section{Erratum to: AIDS Behav \\ DOI 10.1007/s10461-016-1424-8}

Unfortunately, the online published article has errors in Table 4. The sample size for the analyses presented in Table 4 is 62 (not 63) as one outlier reporting 180 condomless anal sex partners was excluded. The correct Table 4 is given in the following page.
Table 4 Hierarchical linear multiple regression predicting number of condomless anal sex partners among HIV-negative and positive transgender women, $N=62$

\begin{tabular}{lllllll}
\hline Predictor variable & $B$ & $p$ & $R^{2}$ & $\Delta R^{2}$ & $\Delta F$ & $p$ \\
\hline Step 1 & & & & & & \\
$\quad$ Age & 0.03 & .69 & .011 & -.045 & 0.20 & .90 \\
$\quad$ Education & 0.43 & .77 & & & & \\
$\quad$ Income & 0.77 & .61 & & & & \\
Step 2 & & & & & & \\
$\quad$ Structural barriers & 0.51 & .001 & .201 & .190 & 12.39 & .001 \\
\hline
\end{tabular}

Excludes outlier reporting 180 condomless anal sex partners

The online version of the original article can be found under doi:10.1007/s10461-016-1424-8.

Jerris L. Raiford

jraiford@cdc.gov

1 Division of HIV/AIDS Prevention, Centers for Disease

Control and Prevention, Atlanta, GA, USA

2 LaGuardia Community College, City University of New York, Long Island City, Queens, NY, USA

3 Graduate Center, City University of New York, New York, NY, USA

4 Center for HIV Educational Studies and Training, New York, NY, USA

5 Hunter College, City University of New York, New York, NY, USA 